\title{
Closure of non-healing gastrocutaneous fistula after percutaneous endoscopic gastrostomy by endoscopic submucosal dissection and over-the-scope clip
}

Fistulous leakage after percutaneous endoscopic gastrostomy (PEG) removal is a common adverse event occurring in around $25 \%$ of patients and requiring surgery in $13 \%$ of patients [1]. Conservative treatment with stomach emptying, silver nitrate, changing of the tube, and promotility agents are usually offered first. Previously persistent fistulas were usually closed surgically, but a variety of different endoscopic techniques that are less invasive than surgery have emerged, includ- ing electrochemical cautery, argon plasma coagulation and associated hemoclip placement [2], percutaneous endoscopic suturing [3], or use of the over-the-scope clip (OTSC) system [4].

We present here the case of an 89-yearold woman who was referred for a persistent gastrocutaneous fistula 20 months after PEG tube removal. The patient had suffered from achalasia, and had failed to improve with peroral endoscopic myotomy (POEM). Therefore, a 20-Fr PEG was inserted for supplemental feeding in February 2015 . Wound infection of the PEG occurred 8 months later, although her oral intake had by then improved, so the PEG tube was removed in August 2017.

A gastric fistula persisted with intermittent liquid leakage, associated with local skin erythema and pain. Conservative treatment failed and a combined endoscopic closure using endoscopic submucosal dissection (ESD) and an OTSC was proposed ( $\vee$ Video 1 ), as previously dem-
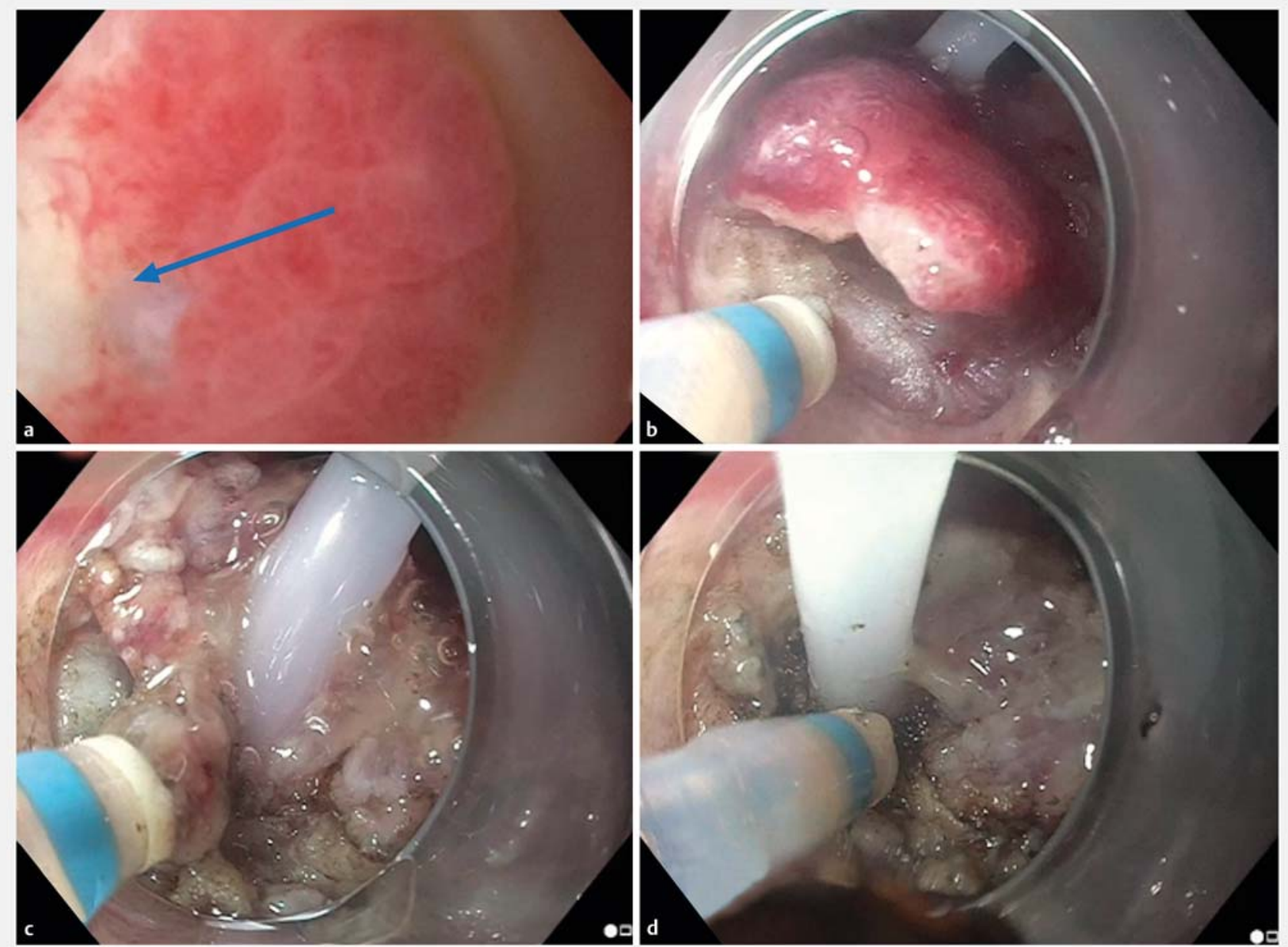

- Fig. 1 Endoscopic images during endoscopic submucosal dissection of a persistent gastrocutaneous fistula after percutaneous endoscopic gastrostomy (PEG) removal showing: a the internal orifice of the fistula (arrow); $\mathbf{b}-\mathbf{d}$ the progressive dissection of the mucosal patch surrounding the fistula until complete ablation of the gastric mucosa. 

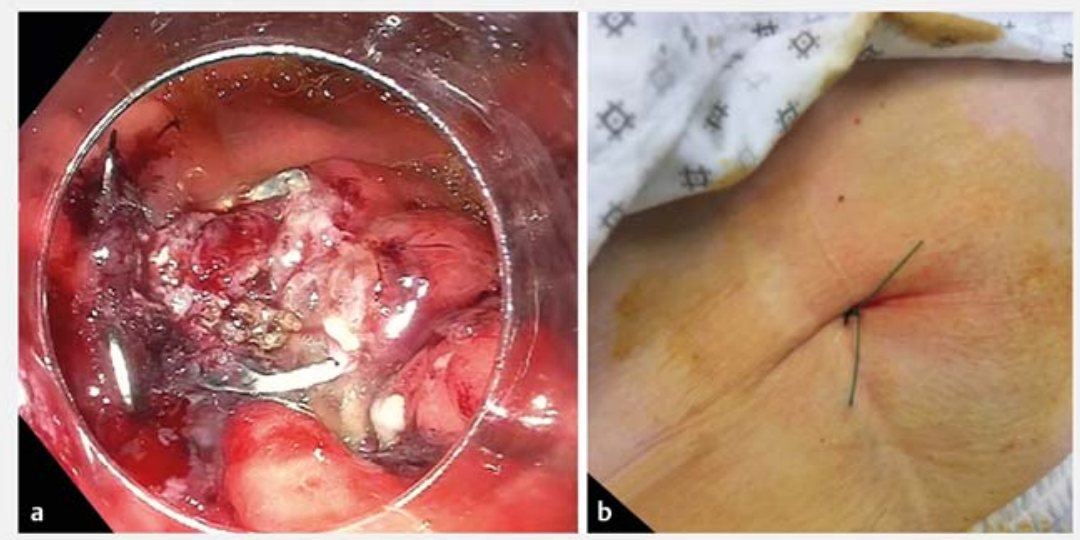

- Fig. 2 The closed fistula seen on: a internal view, showing the over-the-scope clip closure; b external view, showing the closure with a suture.
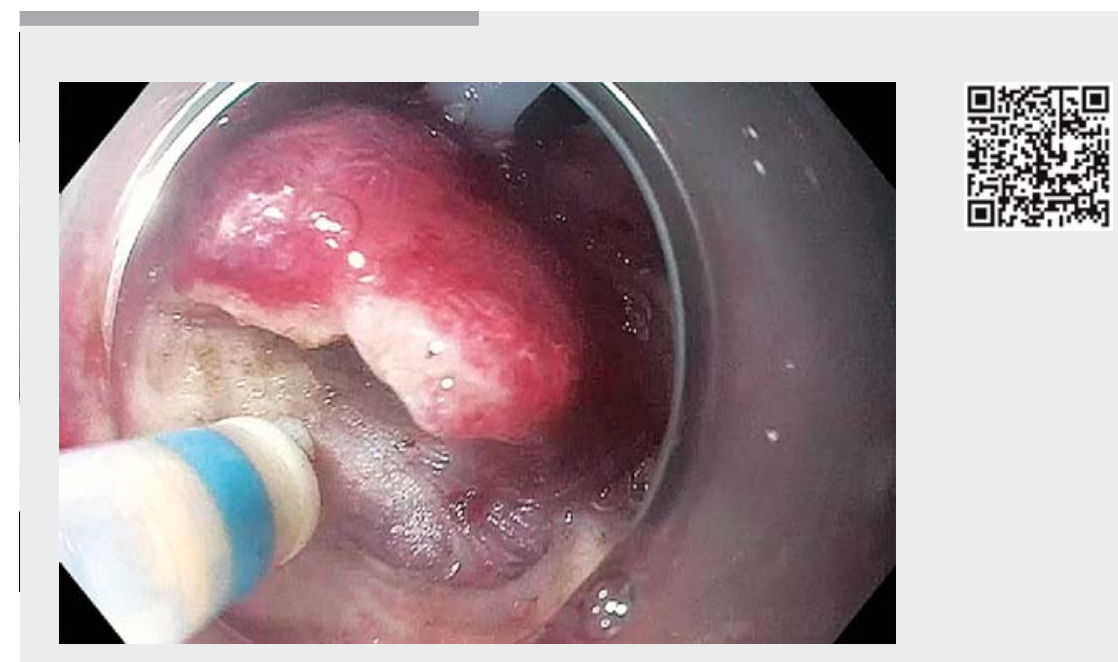

$\checkmark$ Video 1 Procedure of endoscopic submucosal dissection combined with over-thescope clip closure of a chronic gastrocutaneous fistula after percutaneous endoscopic gastrostomy tube removal.

onstrated in other fistulas [5]. The tract was catheterized with a plastic catheter inserted into the center of the fistula ( Fig. 1). A circumferential ESD was performed to ablate the surrounding mucosa and the fistula tract to promote healing. The inner fistula was then closed with an OTSC (Ovesco) ( $\mathbf{F i g . 2 a ) . ~ F i n a l l y , ~ t h e ~}$ skin was sutured (one stitch) to improve scar formation ( $\boldsymbol{\nabla}$ Fig. 2 b).

The patient was discharged on day 1 . The gastrocutaneous fistula was completely healed in less than 1 week and remains closed after 2 months.
Endoscopy enables therapy that is less aggressive than, but as effective as, surgery for the closure of simple fistulas. Combining ESD with the OTSC system offers the ability to trap and hold adequate tissue, which is a limitation of hemoclip application, and favors healing.

Endoscopy_UCTN_Code_TTT_1AO_2AI

Competing interests
The authors

Servane Gay-Chevallier ${ }^{1}$, Alexandru Lupu ${ }^{1}$, Jérôme Rivory ${ }^{1}$, Florian Rostain ${ }^{1}$, Thierry Ponchon ${ }^{1}$, Jean-Christophe Saurin ${ }^{1}$, Mathieu Pioche $^{1,2}$

1 Department of Endoscopy and Gastroenterology, Pavillon L, Edouard Herriot Hospital, Lyon, France

2 Inserm U1032 LabTau, Lyon, France

\section{Corresponding author}

\section{Mathieu Pioche, MD}

Endoscopy unit - Digestive Disease department, Pavillon L - Edouard Herriot Hospital, 69437 Lyon, France mathieu.pioche@chu-lyon.fr

\section{References}

[1] Kobak GE, McClenathan DT, Schurman SJ. Complications of removing percutaneous endoscopic gastrostomy tubes in children. J Pediatr Gastroenterol Nutr 2000; 30: 404 407

[2] Teitelbaum JE, Gorcey SA, Fox VL. Combined endoscopic cautery and clip closure of chronic gastrocutaneous fistulas. Gastrointest Endosc 2005; 62: 432 - 435

[3] Alberti-Flor JJ. Percutaneous-endoscopic suturing of gastrocutaneous fistula: report of 2 cases. Gastrointest Endosc 2002; 56: $751-753$

[4] Heinrich H, Gubler C, Valli PV. Over-thescope-clip closure of long lasting gastrocutaneous fistula after percutaneous endoscopic gastrostomy tube removal in immunocompromised patients: A single center case series. World J Gastrointest Endosc 2017; 9: 85-90

[5] Barsic N, Rivory J, Monneuse O et al. Successful closure of a refractory rectal anastomotic fistula using endoscopic submucosal dissection combined with an over-the-scope clip. Endoscopy 2018; 50: E99-E101

\section{Bibliography}

DOI https://doi.org/10.1055/a-0858-9796

Published online: 13.3.2019

Endoscopy 2019; 51: E125-E126

(c) Georg Thieme Verlag KG

Stuttgart · New York

ISSN 0013-726X 